\title{
DE NOVO ESSA MESMA HISTÓRIA... UMA ANÁLISE DE REPRESENTAÇÕES DO LEITOR POPULAR NO PROGRAMA 'CONTA PRA MIM'
}

\author{
THAT SAME STORY AGAIN... \\ AN ANALYSIS OF REPRESENTATIONS OF THE POPULAR READER IN THE \\ PROGRAM 'CONTA PRA MIM'
}
DE NUEVO ESA MISMA HISTORIA...
UN ANÁLISIS DE LAS REPRESENTACIONES DEL LECTOR POPULAR EN EL PROGRAMA 'CONTA PRA MIM'

\author{
Luzmara Curcino ${ }^{1}$ \\ Adriana Cícera Amaral Fancioº
}

Resumo: Analisa-se, neste trabalho, representações do leitor no programa de incentivo à literacia familiar "Conta pra Mim" (BRASIL, 2020), com foco no excessivo didatismo das orientações e nos falsos endereçamentos de público.

Palavras-chave: Leitor popular; programa de incentivo à leitura; Conta pra mim.

Abstract: This paper analyzes representations of the reader in the program to encourage family literacy "Conta pra Mim" (BRASIL, 2020), focused on the excessive didacticism of the guidelines and the false addressing of the public.

Keywords: Popular reader; reading incentive program; Conta pra mim.

Resumen: Este trabajo analiza las representaciones del lector en el programa de la alfabetización familiar "Conta pra Mim" (BRASIL, 2020), centrándose en el excesivo didactismo de las directrices y el falso direccionamiento del público.

Palabras clave: Lector popular; programa de fomento de la lectura; Conta pra mim.

\section{Políticas, programas e projetos de promoção da leitura}

Não é de hoje que se afirma a urgência e a necessidade de programas de fomento à leitura no Brasil e que devem ser assumidos, sobretudo, por iniciativa governamental, voltados especialmente para o atendimento de crianças, adolescentes e jovens, principalmente aqueles em situação de vulnerabilidade ${ }^{3}$, afinal é papel do Estado promover e mediar certos pactos

\footnotetext{
${ }^{1}$ Universidade Federal de São Carlos - UFSCar.

${ }^{2}$ Universidade Federal de São Carlos - UFSCar.

${ }^{3}$ No Brasil, a desigualdade socioeconômica condena um número importante de famílias a viver em condições de extrema vulnerabilidade, o que aliena, em especial os membros mais jovens, de direitos básicos, como o de moradia, alimentação, saúde e educação decentes. A esse respeito, ver Carvalho (1995); Petrini (2003); Gomes e Pereira (2005), entre outros. No que concerne à cultura, esses membros mais jovens dessas famílias vulneráveis socioeconomicamente são privados, muito cedo, das condições fundamentais para que possam vir a ser leitores. É indispensável o papel do Estado e de políticas públicas interligadas que respondam simultaneamente às necessidades materiais e culturais de seus cidadãos de maneira o mais igualitária possível e urgente. Embora nossa história forneça exemplos de políticas públicas voltadas, por exemplo, para o fomento da leitura, a maior parte delas não esteve à altura do desafio, como bem observaram Britto (1999, 2015), Abreu (2001a), Soares (2001). Algumas, no entanto, deram passos importantes embora tenham sido precocemente interrompidas, conforme demonstraram Amorim (2006) e Marques Neto (2010, 2017).
} 
sociais, necessários para nossa vida em conjunto, em sociedade, estabelecendo um contrapeso à lógica capitalista naturalizada do 'cada um por si' e do 'que vença o melhor'.

Também não é de hoje que testemunhamos a proposição, financiamento e realização, por parte de diferentes governos, de projetos e campanhas em prol dessa prática que, em muitas ocasiões, foram formulados a partir de pressupostos equivocados e que eram efetivamente pouco comprometidos com a realidade social local. Boa parte deles esteve, portanto, desde o início, fadada a obter frágeis e inconsistentes resultados.

O que muitos desses programas, projetos e campanhas ignoraram - por inconsciência, negligência ou estratégia ${ }^{4}$ - é a relação direta e necessária entre as condições sociais e materiais de existência dos indivíduos e as práticas culturais que eles exercem ou não, e que eles podem exercer ou não em função dessas condições ${ }^{5}$. Este é o caso do programa que aqui analisamos.

A leitura é uma dentre várias práticas culturais que só encontra lugar, guarida e possibilidade de ser plenamente realizada se garantidos, minimamente, certos direitos materiais a todos os membros de uma sociedade. Não se pode esperar que as pessoas se tornem leitoras, apenas com a reativação sem fim das mesmas propagandas que pregam em terra de convertidos ao reiterarem, até com um certo grau de cinismo, que 'ler é bom' ${ }^{6}$. Claro que é bom. Isso todos nós sabemos. Sabem disso sobretudo todos aqueles que não puderam se tornar leitores, no sentido pleno do termo, e que sofrem todo dia, na carne, as consequências dessa falta, em uma sociedade que discrimina seus cidadãos também em função de seus dotes culturais ${ }^{7}$.

Dizemos ler é bom, ler é importante, ler muda vidas, e atuamos como sociedade, em um 'descuido' programado e antigo e de diversas facetas, que vem sistematicamente impedindo que a maioria dos brasileiros acedam igualitariamente à escola, ao saber de prestígio, às práticas culturais legitimadas, tais como a leitura, e aos objetos materiais que dão acesso a esse saber e ao exercício dessas práticas, tais como o livro. Como sociedade, convivemos com uma oferta restrita, irregular, e ainda mais perversa em alguns casos quando se seleciona obras e versões de obras em função da origem social daqueles para quem são destinadas em programas governamentais. Não se democratiza a leitura com o acesso a livros ruins, com ideias equivocadas, em usos utilitaristas. O descuido com o tipo de obra disponibilizada é também uma forma de alienação relacionada à formação leitora, como o que ocorre com as adaptações de contos de fada que foram produzidas como parte do material didático do programa aqui em análise.

Em geral, programas como este e suas ações não se inscrevem em projetos mais amplos e articulados com outras medidas, que assim enfrentem em conjunto as verdadeiras razões que impedem à maioria de nós de ter acesso à leitura e de nos tornarmos, efetivamente, leitores. Essas razões, embora conhecidas, são sistematicamente ignoradas, silenciadas e obliteradas na elaboração desses programas ${ }^{8}$.

\footnotetext{
${ }^{4}$ Segundo Darcy Ribeiro (2018), a crise da Educação no Brasil não é uma crise, é um projeto.

${ }^{5}$ Uma honrosa exceção de nossa história de projetos, programas e políticas públicas equivocadas na promoção da leitura é aquela encampada por José Castilho Marques Neto, responsável pela Política Nacional de Leitura e Escrita (PNLE), que estabelece estratégias para a universalização do direito ao acesso ao livro, à leitura, à escrita, à literatura e às bibliotecas, formulada após amplo debate com todos os agentes e setores envolvidos, baseada no conhecimento da realidade brasileira.

${ }^{6}$ Uma série de campanhas de promoção da leitura foi construída com base em mitos, descolados da realidade dos sujeitos e de suas práticas, conforme discutido por Luiz Percival Leme Britto e Valdir Barzotto (1998); Britto (1999; 2015); Varella e Curcino (2014).

${ }^{7}$ Tal como observa Curcino (2020), justamente aqueles que são sistematicamente alienados do direito à leitura têm plena consciência de seu papel determinante de sua condição uma vez que essa prática é usada regularmente como justificativa para a naturalização e manutenção das diferenças sociais, para explicar por que as pessoas são pobres e outras não, e para perversamente responsabilizar os indivíduos pela "decisão" de ser ou não leitor. ${ }^{8}$ A respeito desse descaso estratégico ver Freire (1987); Soares (2001) e Silva (1997).
} 
As condições sociais, econômicas e culturais responsáveis pela vergonhosa desigualdade brasileira são, não por mera coincidência, as razões que impedem a maioria dos brasileiros de se tornarem leitores plenos. Tal como afirmam, entre outros, Paulo Freire (1987), Márcia Abreu (2001b) e Luiz Percival Leme Britto (2015), aqueles que no Brasil não são leitores são justamente os mesmos sujeitos que não têm moradia, terra, trabalho digno, saúde e educação de qualidade.

Não se trata de mera coincidência. Se não deve negar a relação necessária, evidente, de causa e consequência entre não ser leitor e não ter casa, nem trabalho, nem formação digna. Não se pode negar também que um dos empecilhos para alguém se formar leitor é justamente aquele da impossibilidade de sua identificação com a versão idealizada, romantizada e despolitizada acerca da leitura e do que é ser leitor. Em geral, de tudo o que ouvimos sobre a leitura vemos, em grande medida uma exaltação alienada quanto a seu poder de mudança dos sujeitos e de suas condições de vida. A leitura, de fato, pode desempenhar esse papel dependendo do que se entende por leitura, do que se quer promover quando se promove a leitura, dos compromissos honestos, igualitários, humanizados e políticos de quem a fomenta, e do que se faz para garantir sua difusão e sua força emancipadora e crítica. Sem esse compromisso, a ênfase nesse poder da leitura pode inclusive ser um meio de justificar porque alguns na sociedade são melhores que outros, se esforçaram mais, se formaram leitores, e por isso merecem ter acesso a bens e condições mais dignas que outros não merecem por não terem se esforçado. Uma lição que aprendemos com a Análise do Discurso de tradição francesa, na qual se inscrevem autores como Michel Pêcheux (2008) e também algumas obras de Michel Foucault (1999), é a de analisar o enunciado em seu acontecimento, ao mesmo tempo ligado à materialidade específica do enunciado efetivamente formulado e às condições históricas de sua produção, que implicam nos perguntarmos quem fala, de onde fala, segundo que inscrição ideológica, de que posição discursiva. Mais do que reproduzir discursos validados e tornados consensos sociais sobre a leitura, é preciso sempre nos perguntar de onde partem e com que objetivos. Mais do que afirmar que é importante ler e ler para as crianças, seria importante para qualquer iniciativa governamental minimamente responsável garantir a possibilidade de ler a todos os cidadãos, garantir esse direito inalienável à leitura ${ }^{9}$.

Apesar de já termos caminhado bastante, no campo dos estudos sobre a leitura, quanto a essa compreensão dos diversos fatores que participam decisivamente da formação de um leitor, assistimos hoje à promoção de um programa governamental de incentivo a essa prática aos moldes desse modelo propagandístico antiquado, populista, pouco eficaz e excludente, que reativa discursos idealizados e hegemônicos sobre essa prática e que, a reboque, reiteram a transferência de responsabilidades do Estado para os indivíduos. Este programa do governo atual traz uma série de marcas das demais ações por ele encaminhadas. Investe em ações que visam incutir ainda mais esse paralelismo entre ler e melhorar de vida ao mesmo tempo em que conduz políticas econômicas e sociais segundo as quais se isenta da responsabilidade pública quanto à garantia que isso de fato se dê. A irresponsabilidade estratégica de sua gestão econômica compromissada em atender as elites econômicas nacionais e internacionais predatórias das riquezas e bens públicos, necessita de programas culturais, educacionais que a blindem ou a justifiquem, que naturalizem as ideias perversas do ultraliberalismo e da meritocracia, de modo a justificar porque parte da sociedade goza de privilégios e a outra, a maioria de nós, não.

E um exemplo de indiferença em relação a essas condições sociais, assim como de reativação de discursos cínicos sob a forma de propagandas de promoção da leitura que repetem o que em geral é sabido de todos, é o do programa do governo federal atualmente em vigor, de

\footnotetext{
${ }^{9}$ Entre as contribuições fundamentais de intelectuais brasileiros sobre a leitura como um direito, ver Candido (2004), ao defender o papel humanizador da ficção e especialmente da leitura literária, o estudioso afirma ser este um direito incompressível, fundamental, que não pode ser negado, tal como outros direitos humanos.
} 
iniciativa do Ministério da Educação, intitulado Conta pra Mim (BRASIL, 2019c; 2020), engajado na promoção da prática de 'literacia familiar'.

Em 11 de abril de 2019, quando se completaram 100 dias do governo eleito. Entre as ações que tradicionalmente se apresenta nessa ocasião simbólica para a política como sendo aquelas que darão o 'tom' a toda a gestão em curso, nos mais diferentes setores da administração pública, o governo federal, por meio de decreto do Ministério da Educação (MEC) sob a batuta do ex-ministro Abraham Weintraub, lançou a Política Nacional de Alfabetização (PNA), de responsabilidade da Secretaria de Alfabetização (SEALF). Segundo afirmou Carlos Francisco de Paula Nadalim, secretário encarregado dessa política, o objetivo do PNA é o de "elevar a qualidade da alfabetização e combater o analfabetismo em todo o território brasileiro" (BRASIL, 2019a, p. 7). Entre as ações dessa política, foi instituído o referido programa Conta pra Mim, por meio da portaria n. 421, de 24 de abril de 2020 do MEC (BRASIL, 2020).

O referido programa, tal como se apresenta, é destinado a promover o que designa como "literacia familiar", a saber, uma série de condutas educacionais que adultos responsáveis por crianças, tanto aquelas ainda não escolarizadas quanto aquelas que já frequentam a escola nas séries iniciais, devem dominar para garantir uma melhor formação dessas crianças. Esse público adulto genérico é a quem se dirige grande parte das ações do programa com vistas a orientar e auxiliar suas atitudes, em especial, no estímulo à leitura, contemplando, sobretudo, crianças provenientes de famílias socialmente carentes. Na portaria que institui o programa Conta pra Mim, afirma-se que "é considerado público-alvo do programa todas as famílias brasileiras, tendo prioridade aquelas em condição de vulnerabilidade socioeconômica" (BRASIL, 2020, p. 181, grifos nossos).

Como justificativa de sua relevância e urgência, os promotores dessa política dizem basear-se em "pesquisas que mostram [haver] entre as famílias pobres e as famílias de classe média alta, um abismo tanto na qualidade quanto na quantidade das interações verbais entre pais e filhos" (BRASIL, 2020b, [n. p.]). Ainda segundo o programa, "crianças criadas em lares onde os pais promovem a Literacia Familiar se tornam melhores leitores e estudantes mais bemsucedidos" (BRASIL, 2020b, [n. p.]).

Entre as práticas que se visa estimular, observa-se a prioridade outorgada à leitura. Ela se encontra explicitada em diferentes documentos e materiais que instituem e compõem o programa, como na nota do então Ministro da Educação, Abraham Weintraub, quando afirma que a PNA "pretende oferecer às redes e aos alunos brasileiros, por meio de programas e de ações, a valiosa contribuição das ciências cognitivas, especialmente da ciência cognitiva da leitura" (BRASIL, 2019a, p. 5).

É possível, até aqui, afirmar i) a centralidade da leitura no conjunto das práticas que o programa visa fomentar; ii) a destinação prioritária, ao menos na letra da lei, às "famílias pobres", em "condição de vulnerabilidade socioeconômica"; iii) o pressuposto de que as crianças com essa origem são aquelas menos expostas a práticas necessárias para sua formação cultural, leitora; iv) a reiterada afirmação de que o programa e as ações recomendadas sustentam-se em uma perspectiva científica sólida, consequente, autossuficiente e efetivamente eficiente.

Nada na política de alfabetização e no programa Conta pra mim foge às linhas de força ideológicas da política do atual governo. Por um lado, seu estilo declarativo, segundo o qual se reitera seu caráter não ideológico, em benefício do alegado caráter técnico que nortearia suas decisões. Estamos diante aqui de uma estratégia argumentativa que havia sido empregada ao longo de toda a campanha eleitoral do atual governo: a de negar a realidade de que suas posições e decisões políticas fossem ideológicas, como o são toda e qualquer posição e decisão política; e a de condenar o caráter ideológico na política como se fosse algo exclusivo da esquerda e, assim sendo, como se isso fosse algo ruim. Por outro lado, se observa o profundo alinhamento desse governo a ideias e práticas da direita e extrema-direita norte-americanas e europeias, muitas vezes em conflito 
com o alegado patriotismo ou nacionalismo também muito explorado na campanha política bolsonarista. Para validar 'tecnicamente' a política educacional priorizada por este governo, se ignorou a produção científica, reconhecida nacional e internacionalmente, de pesquisadores brasileiros que há décadas se dedicam aos estudos sobre a alfabetização e sobre o ensino e fomento da leitura no Brasil considerando nossa realidade social, e se adotou uma terminologia técnica importada, da qual é um exemplo flagrante o emprego do termo "literacia", derivado do inglês "literacy", para a designação conceitual de práticas já identificadas, descritas e estudadas no Brasil, e sobre as quais dispomos de uma ampla bibliografia qualificada, sob a designação "letramento".

A questão que deve reter nossa atenção nessa escolha terminológica, conforme pondera Clécio Bunzen $(2019 ; 2021)$, não se resume apenas à mera predileção por um termo técnico concebido e empregado em outros países. A questão implica um posicionamento ideológico bem específico: aquele de buscar termos em outras culturas para se distinguir de toda a tradição de estudos realizados sobre a alfabetização por pesquisadores brasileiros de renome, e aquele de reduzir a semântica desses termos à promoção de práticas comprometidas com a ideologia de desmonte do Estado, da escola pública, de sua função socializadora, de modo a justificar práticas como a de homeschooling à americana.

O programa também representa bem o ultraliberalismo político-econômico adotado pelo atual governo quando, mesmo em ações do Estado para a promoção da formação cultural da população, se transfere a responsabilidade deste para esta, vista não como uma coletividade marcada por divisões sociais e hierárquicas que excluem a maioria, mas como resultante da soma de indivíduos responsáveis diretamente por seu sucesso ou infortúnios. Ao outorgar às famílias a responsabilidade por determinadas ações educacionais, sob o pretexto de garantir um melhor desempenho das crianças em atividades escolares, o programa atualiza não apenas a ideia de estado mínimo, mas de estado bem ao estilo de Pilatos, que transfere obrigações e que lava as mãos de seu papel como agente fundamental para a manutenção do ainda muito frágil pacto social estruturado em nossa constituição.

É com vistas à análise discursiva mais pontual de alguns enunciados oriundos do conjunto documental que institui e divulga o programa Conta pra mim que, neste artigo, buscamos depreender algumas representações da leitura e dos leitores.

\section{O incentivo à leitura em Conta pra mim: um real que se ignora ou o mero cinismo de classe?}

Dos materiais que compõem o acervo de textos relativos ao programa, o Guia de Literacia Familiar se destina, conforme anunciado no documento, a orientar os pais ou responsáveis quanto às práticas a adotar e quanto ao modo de empreendê-las. Para isso, é preciso fazer a propaganda do caráter 'técnico' de sua formulação e de suas proposições, é preciso convocar e apresentar conceitos que garantam o 'lastro' científico necessário em programas nacionais destinados a intervir na educação no país. Para afirmar o caráter científico, mas também inovador da proposta, os enunciadores do Guia apresentam uma explanação o mais detalhada possível do principal conceito norteador da proposta, o de "Literacia Familiar":

Literacia Familiar é o conjunto de práticas e experiências relacionadas com a linguagem oral, a leitura e a escrita, que as crianças vivenciam com seus pais ou responsáveis.

É interagir, conversar e ler em voz alta com os filhos. É estimulá-los a desenvolver, por meio de estratégias simples e divertidas, quatro habilidades fundamentais: ouvir, falar, ler e escrever!

Literacia Familiar é se envolver na educação dos filhos, curtindo momentos especiais de afeto, carinho e diversão em família, brincando com livros e palavras. 
Não é preciso ter muito estudo, materiais caros nem morar em uma casa toda equipada e espaçosa para praticar a Literacia Familiar. As práticas de Literacia Familiar são acessíveis a todos! Bastam duas coisas: você e seu filho! As práticas de Literacia Familiar podem começar durante a gestação e se estender até o final da adolescência. Literacia Familiar é o reconhecimento de que os pais são os primeiros professores de seus filhos (BRASIL, 2019c, p. 13, grifos nossos).

Nessa definição apresentada no Guia, observamos tanto a preocupação em ter 'um conceito científico para chamar de seu' como também um excesso de didatismo, expresso entre outros elementos pela: i) repetição da designação "Literacia Familiar"; ii) pelo emprego de um léxico simples com a presença de termos da oralidade, como gírias ("curtindo"); iii) por uma representação gráfica enumerada da sintaxe de períodos compostos divididos como se fossem períodos simples, estruturados de forma acumulativa e por coordenação. Essas escolhas linguísticas das formas de enunciar adotadas pelos enunciadores no texto deste Guia parecem responder à imagem genérica, simplista e enviesada que é feita do público para o qual o programa se destina, conforme a portaria que institui o programa, a saber: "todas as famílias brasileiras, tendo prioridade aquelas em condição de vulnerabilidade socioeconômica” (BRASIL, 2020a, Art. $2^{\circ}$, grifo nosso).

Esse excessivo didatismo também responde a essa imagem miserabilista do públicoalvo, ao se afirmar, no texto do próprio Guia, e nessa sequência enunciativa, que "Não é preciso ter muito estudo, materiais caros nem morar em uma casa toda equipada e espaçosa para praticar a Literacia Familiar. Ela é acessível a todos! Bastam duas coisas: você e seu filho!" (BRASIL, 2019c, p. 13, grifo nosso).

Para se justificar socialmente, o programa Conta pra mim é destinado prioritariamente às famílias em "condição de vulnerabilidade socioeconômica". No entanto, uma série de ações de divulgação do programa destoam dessa destinação. Talvez a mais grave delas seja a do lançamento do programa nos principais Shoppings Centers das capitais brasileiras.

Em um ato talvez não falho de reconhecimento das contradições do programa, o enunciador, ao apresentar a proposta, recorre a uma série de negativas metalinguísticas, que são semânticas ou pragmaticamente ambíguas. Essas negações ("não é preciso ter muito estudo", "[nem] materiais caros", "nem morar em uma casa equipada") refutam por antecipação críticas prováveis e plausíveis em relação à proposta ${ }^{10}$. Ao se afirmar algo por meio da negação antecipada de críticas, visa-se contra-argumentar, previamente, as denúncias do caráter alienado da proposta e do profundo desconhecimento, ou indiferença, de seus formuladores em relação à realidade das famílias brasileiras, de suas reais condições materiais e econômicas, que são o empecilho efetivo à formação leitora da maioria da população.

Antecipando o questionamento da viabilidade do programa, o texto do Guia afirma enfaticamente que "As práticas de Literacia Familiar são acessíveis a todos!" (BRASIL, 2019c, p. 13, grifos nossos). Essa afirmação parece ser aquela da ordem mística que se atribui a falas performativas, aquelas que uma vez enunciadas, uma vez a ação afirmada enunciativamente, logo, a ação é realizada. Nessa promessa de que todos são convidados para o banquete, não se diz que poucos são os escolhidos. Com uma consulta rápida a dados sociológicos obtidos e divulgados pelo Censo nacional realizado pelo Instituto Brasileiro de Geografia e Estatística (IBGE), e outras pesquisas nacionais, seria possível saber que essa afirmação da acessibilidade a todos é tão ficcional quanto as adaptações dos contos de fadas propostas pelo programa.

\footnotetext{
${ }^{10}$ A negação metalinguística é caracterizada como uma negação que se contradiz para refutar um discurso. Entre vários autores que a definem, ver Indursky (1990), em complemento às considerações de Ducrot (1987) e Negroni (2009).
} 
Ignora-se a realidade da maioria das famílias brasileiras ao se pressupor: i) que os pais ou adultos responsáveis a quem se dirigem as ações do programa sejam alfabetizados e que disponham de um grau de letramento que lhes permita acessar todo esse material disponibilizado virtualmente no site do MEC de modo a poderem se dedicar às práticas ali sugeridas; ii) que as famílias sejam constituídas por mais de adulto responsável, quando sabemos que a maioria de nossas famílias é monoparental, com mulheres como provedoras da família, com duplicação ou triplicação de turnos e obrigações; iii) que estes adultos disponham de meios materiais para acessar virtualmente esses materiais (internet, computador, celular, impressora); iv) que disponham ainda de tempo, atributo essencial tanto para prover a atenção às necessidades básicas das crianças (alimentação, higiene, saúde, segurança) quanto suficiente e de qualidade para realizar as ações previstas no Guia; v) de espaço adequado, confortável, digno, tranquilo e seguro necessário para se promover essas práticas enumeradas no programa, em especial a da leitura; v) que disponham de energia e humor, assim como condições culturais, psicológicas, intelectuais e afetivas para exercitar essas práticas de forma lúdica, serena, prazerosa com os filhos, tal como idealizada no programa "curtindo momentos especiais de afeto, carinho e diversão em família, brincando com livros e palavras" (BRASIL, 2019c, p. 13).

Nada mais alheio à realidade da maioria das famílias brasileiras!

Por isso, é extremamente falacioso afirmar que "Bastam duas coisas: você e seu filho!" (BRASIL, 2019c, p. 13). Além de não ser verdade, há com este tipo de enunciação uma transferência perversa de responsabilidades do Estado para os indivíduos, que em concorrência à escola, e sem uma formação específica, sem tempo e dinheiro, e por isso reféns das prioridades de sobrevivência do dia a dia, ainda mais diante das políticas atuais que intensificaram a precarização das condições de trabalho, ainda assim, são esses indivíduos aqueles que são instados a se encarregar dessa formação paralela ou antecipada à atuação da escola.

Além da indiferença a esses aspectos materiais concretos da vida da maioria das famílias brasileiras, e da arrogância e cinismo implicados nessa proposta alienada, é preciso considerarmos ainda outro empecilho decisivo para o sucesso que se visa obter com ações como estas. Trata-se de um empecilho de ordem simbólica, da ordem da identificação. A maioria das famílias brasileiras, dadas suas carências socioeconômicas, é obrigada a antecipar junto a seus filhos o senso de realidade, de necessidade e de obrigação a que suas condições sociais a submetem, e isso desde muito cedo, de modo a, de antemão, os filhos das famílias pauperizadas terem de escolher aquilo que já lhes foi destinado socialmente ${ }^{11}$, e com isso terem de otimizar suas ações priorizando aquelas com finalidades pragmáticas mais imediatas e necessárias a sua sobrevivência.

Em paralelo aos documentos oficiais que regem e apresentam as diretrizes do Conta pra mim, há os materiais de divulgação do programa, compostos de propagandas audiovisuais e de vídeos promocionais de circulação na TV e em vários canais da internet. Neles é ainda mais flagrante o desencontro entre a representação das famílias para as quais se destina o programa e as famílias brasileiras propriamente ditas.

As famílias ficcionais dos vídeos, nessa sua representação distópica de propaganda de margarina, são compostas de casais heterossexuais representando os avós, os pais e suas crianças, bem-vestidos, em encontros festivos familiares (festas natalinas), em casas confortáveis, decentes e decoradas. Em uma dessas casas-cenário podemos ver, entre cortinas, quadros, tapetes e móveis de design, uma lareira acesa. É o típico cenário de casas de famílias de classe média ou alta, particularmente do sul e sudeste do país, e não necessariamente coincidente com as casas da maior parte das famílias brasileiras, e de modo algum parecida com as casas onde residem aquelas em "vulnerabilidade social".

\footnotetext{
${ }^{11}$ Essa "escolha" dos indivíduos, de antemão induzida pela classe a que se pertence, é abordada de forma incisiva e esclarecedora por Bourdieu e Passeron (2014).
} 
Lançada a propaganda audiovisual, em dezembro de 2019, nos principais canais de TV, suas imagens ilustram a contradição entre o que é enunciado sobre o público a que se destinam as ações do programa e o público representado nesses vídeos.

É inegável a disparidade entre o que é afirmado no texto da "lei" e a realidade das famílias brasileiras, bem como há uma disparidade do que é mostrado no material de promoção do programa com a existência material de nossas famílias. Parece haver entre esses enunciados, materializados nesses dois gêneros e nessas diferentes linguagens do material de institucionalização e de divulgação do programa, uma pronta e imediata incoerência, uma espécie de dissonância entre o que se enuncia como objetivo em um gênero e o que se mostra como representação do ideal no outro, entre as famílias anunciadas como sendo o público-alvo principal do programa e as famílias representadas nos vídeos de propaganda.

As imagens da lareira, da grande e iluminada árvore e de seus enfeites de $\mathrm{Natal}^{12}$, dos muitos presentes, dos gestos dos membros da família reunida para festejar essa circunstância com mesa farta, representam cenas, rituais e pessoas idealizados, sem uma relação empírica com a realidade concreta da maioria dos brasileiros. É flagrante o abismo social entre a realidade dos herdeiros encenados e estetizados nesses vídeos e os não-herdeiros a quem são dirigidos o programa e seus materiais ${ }^{13}$. O público-alvo principal ao qual o programa diz se dirigir torna-se uma abstração propagandística. Ele não apenas não é conhecido e reconhecido em sua especificidade, em sua existência, pelos responsáveis pelo programa, como também é apagado e invisibilizado em sua existência precária, nesses vídeos com famílias da publicidade de margarina. Trata-se, em grande medida, de uma violência simbólica em relação a essas famílias e suas vidas não representadas.

\section{Algumas considerações}

O que assistimos hoje, no Brasil, no que diz respeito ao fomento da leitura é uma versão requentada, populista e alienada quanto às devidas ações e medidas a serem adotadas no incentivo qualificado e massivo à realização dessa prática, sobretudo nas séries iniciais.

$\mathrm{O}$ excessivo didatismo das orientações, as contradições ou os falsos endereçamentos de público e os frágeis pressupostos, tanto teóricos quanto metodológicos, da proposta que se apresenta como científica, técnica, e pretensamente infalível, relacionam-se a representações miserabilistas do povo brasileiro, com soluções perversas de transferência de responsabilidades institucionais e coletivas do Estado para a iniciativa privada, individual, familiar, demonstrando seja um profundo desconhecimento da realidade das famílias brasileiras, seja uma cínica indiferença a suas condições materiais, a sua estrutura, a suas penúrias e a sua exposição constante às violências simbólicas e físicas que sua condição social precarizada lhes impõem, de forma naturalizada.

\section{Referências}

ABREU, Márcia. Diferença e desigualdade: preconceitos em leitura. In: MARINHO, M. (Org.). Ler e navegar: espaços e percursos da leitura. Campinas: Mercado de Letras, 2001a, p. 139-157.

\footnotetext{
12 Vídeo de propaganda do programa Conta pra mim, disponibilizado em 05 de dezembro de 2019 no Portal do MEC, em seu canal no Youtube, como parte da Política Nacional de Alfabetização. Disponível em: https://www.youtube.com/watch? $\mathrm{v}=4 \mathrm{~h} 6 \mathrm{hr}--\mathrm{ndDk} \& \mathrm{t}=14 \mathrm{~s}$.

${ }^{13}$ Essas categorias, de "herdeiros" e de "não-herdeiros", foram propostas por Bourdieu e Passeron (2014) para explicar como sujeitos provenientes de camadas distintas da sociedade naturalizam precocemente as divisões sociais e as distribuições desiguais dos bens de consumo em função do acesso de que dispõem aos mesmos.
} 
ABREU, Márcia. Diferentes formas de ler. In: CONGRESSO BRASILEIRO DE CIÊNCIAS DA COMUNICAÇÃO, 24., 2001, Campo Grande. Anais [...] vol. 1. Campo Grande, 2001b, [n. p.]. Disponível em: http://www.unicamp.br/iel/memoria/Ensaios/Marcia/marcia.htm. Acesso em: 04 jun. 2021.

AMORIM, Galeno. Políticas públicas do livro e leitura. São Paulo: Cultura Acadêmica, 2006.

BRASIL. Ministério da Educação. Secretaria de Alfabetização. PNA política nacional de alfabetização/secretaria de alfabetização. Brasília: MEC, SEALF, 2019a. Disponível em: http://portal.mec.gov.br/images/banners/caderno_pna_final.pdf. Acesso em: 20 ago. 2021.

BRASIL. Decreto n. 9.765, de 11 de abril de 2019. Institui a Política Nacional de Alfabetização. Diário Oficial da União. Brasília, edição: 70-A. seção: 1 - extra, p. 15, 2019b. Disponível em: https://www.planalto.gov.br/ccivil_03/_ato2019-2022/2019/decreto/d9765.htm. Acesso em: 27 ago. 2021.

BRASIL. Ministério da Educação. Secretaria de Alfabetização. Conta pra mim: guia de literacia familiar. Brasília: MEC, SEALF, 2019c. Disponível em: https://alfabetizacao.mec.gov.br/images/pdf/conta-pra-mim-literacia.pdf. Acesso em: 28 ago. 2021.

BRASIL. Ministério da Educação. Gabinete do Ministro. Portaria n ${ }^{\circ} 421$, de 23 de abril de 2020, Institui o Conta pra Mim, programa de literacia familiar do Governo Federal. Diário Oficial da União. Brasília, $\mathrm{n}^{\mathbf{o}}$ 78, p. 181, 24 de abril de 2020a. Disponível em: https://www.in.gov.br/en/web/dou/-/portaria-n-421-de-23-de-abril-de-2020-253758595.

Acesso em: 27 ago. 2021.

BRASIL. Ministério da Educação. Evidências. Política Nacional de Alfabetização - PNA, 2020b. Disponível em: https://alfabetizacao.mec.gov.br/contapramim\#literacia_familiar. Acesso em: 27 ago. 2021.

BRITTO, Luiz Percival Leme. A leitura e sua promoção. In: No lugar da leitura - biblioteca e formação. Rio de Janeiro: Edições Brasil Literário, 2015. p. 24-44.

BRITTO, Luiz Percival Leme. Máximas impertinentes. In: PRADO, J.; CONDINI, P. (Org.). A formação do leitor: pontos de vista. Rio de Janeiro: Argus, 1999. p. 101-107.

BRITTO, Luiz Percival Leme; BARZOTTO, Valdir Heitor. Promoção X mitificação da leitura. Em Dia: Leitura \& Crítica, Campinas, ago. 1998, [n. p.].

BOURDIEU, Pierre; PASSERON, Jean Claude. Os herdeiros: os estudantes e a cultura. Florianópolis: EdUFSC, 2014.

BUNZEN, Clécio. Letramento e/ou literacia? Entrevista com Clecio Bunzen (UFPE) sobre diferenças conceituais e práticas dos termos relacionados a políticas, estudos, ensino e aprendizagem da língua escrita. [Entrevista cedida a] Portal CENPEC Educação. CENPEC, 09 de dezembro de 2019, [n. p.]. Disponível em: https://www.cenpec.org.br/tematicas/letramentoe-ou-literacia-distincoes-e-aproximacoes. Acesso em: 27 ago. 2021. 
BUNZEN, Clécio. A "literacia familiar" substitui o que a escola pode fazer? In: Troca de ideias. Centro de alfabetização, leitura e escrita - CEALE. FaE/UFMG, 06 de agosto de 2021, [n. p.]. Disponível em: https://www.ceale.fae.ufmg.br/pages/view/a-literacia-familiar-substitui-o-quea-escola-pode-fazer.html. Acesso em: 27 ago. 2021.

CANDIDO, Antonio. O direito à literatura. In: CANDIDO, Antonio. Vários escritos. São Paulo: Duas Cidades; Rio de Janeiro: Ouro sobre Azul, 2004. p. 169-191. Disponível em: https://edisciplinas.usp.br/pluginfile.php/4208284/mod_resource/content/1/antonio-candidoo-direito-a-leitura.pdf. Acesso em: 27 set. 2021.

CARVALHO, Maria do Carmo Brant. A priorização da família na agenda da política social. In: CARVALHO, Maria do Carmo Brant. A família contemporânea em debate. São Paulo: Cortez, 1995. p. 11-21.

CURCINO, Luzmara. Infames e penetras no universo da leitura: princípios da arqueologia foucaultiana em uma análise de discursos sobre essa prática. Moara, v. 1, n. 57, p. 74-91, ago./dez. 2020. Disponível em: https://periodicos.ufpa.br/index.php/moara/article/view/8874. Acesso em: 27 set. 2021.

DUCROT, Oswald. Esboço de uma teoria polifônica da enunciação. In: DUCROT, Oswald. $O$ dizer e o dito. Campinas: Pontes, 1987. p. 161-218.

FREIRE, Paulo. Pedagogia do oprimido. Rio de Janeiro: Paz e Terra, 1987.

FOUCAULT, Michel. A ordem do discurso - aula inaugural no Collège de France, pronunciada em 2 de dezembro de 1970. São Paulo: Edições Loyola, 1999.

GOMES, Mônica Araújo; PEREIRA, Maria Lúcia Duarte. Família em situação de vulnerabilidade social: uma questão de políticas públicas. Ciência \& Saúde Coletiva, v. 10, n. 2, p. 357-363, 2005. Disponível em: https://www.scielosp.org/article/csc/2005.v10n2/357363/. Acesso em: 20 nov. 2020.

INDURSKY, Freda. Polêmica e denegação: dois funcionamentos discursivos da negação. Cadernos de Estudos Linguísticos, Campinas, v. 19, p. 117-122, jul./dez. 1990.

MARQUES NETO, José Castilho (Org.). PNLL: textos e história. São Paulo: Cultura Acadêmica Editora, 2010.

MARQUES NETO, José Castilho. Livro e biblioteca em tempos sombrios. In: FERREIRA, M. M. (Org.). Livro, leitura e bibliotecas em tempos sombrios. São Luís: EdUFMA, 2017. p. 31-54.

NEGRONI, Maria Marta García. Negación y descalificación: a propósito de la negación metalinguística. Ciências \& Letras, Porto Alegre, n. 45, jan./jun. 2009, p. 61-82.

PÊCHEUX, Michel. O discurso: estrutura ou acontecimento. Campinas: Pontes, 2008.

PETRINI, João Carlos. Pós-modernidade e família. Bauru: EdUSC, 2003. 
RIBEIRO, Darcy. Educação como prioridade. São Paulo: Editora Global, 2018.

SILVA, Ezequiel Theodoro. Leitura e realidade brasileira. Porto Alegre: Mercado Aberto, 1997.

SOARES, Magda. As condições sociais da leitura: uma reflexão em contraponto. In: ZILBERMAN, R.; SILVA, E. T. (Org.). Leitura: perspectivas interdisciplinares. São Paulo: Editora Ática, 2001. p. 18-29.

VARELLA, Simone Garavello; CURCINO, Luzmara. Discursos sobre a leitura: uma análise de vídeo-campanhas em prol dessa prática. Revista Desenredo, v. 10, p. 337-354, 2014. Disponível em: http://www.upf.br/seer/index.php/rd/article/view/4157/3091. Acesso em: 15 set. 2021.

\section{Sobre as autoras}

Luzmara Curcino. Professora no Departamento de Letras e no Programa de Pós-Graduação em Linguística da Universidade Federal de São Carlos. Coordenadora do Laboratório de Estudos da Leitura (LIRE-CNPq/UFSCar).

E-mail: $\underline{\text { luzcf@ufscar.com. }}$

Adriana Cícera Amaral Fancio. Graduada em Letras e em Pedagogia, mestre em Educação pela Universidade Federal de São Carlos e Doutoranda em Linguística pelo Programa de PósGraduação em Linguística (PPGL) desta mesma Universidade e Pesquisadora no Laboratório de Estudos da Leitura (LIRE-CNPq/UFSCar).

E-mail: adriana.cicera@hotmail.com. 